\title{
Interleukin-6 gene knockout antagonizes high-fat-induced trabecular bone loss
}

\author{
Chunyu Wang*, Li Tian*, Kun Zhang, Yaxi Chen, Xiang Chen, Ying Xie, \\ Qian Zhao and Xijie Yu
}

Laboratory of Endocrinology and Metabolism, Department of Endocrinology, State Key Laboratory of Biotherapy and Cancer Center, West China Hospital, Sichuan University, Chengdu, Sichuan, People's Republic of China *(C Wang and L Tian contributed equally to this work)

\begin{abstract}
The purpose of the study was to determine the roles of interleukin-6 (IL6) in fat and bone communication. Male wild-type (WT) mice and IL6 knockout (IL6 ${ }^{--}$) mice were fed with either regular diet (RD) or high-fat diet (HFD) for 12 weeks. Bone mass and bone microstructure were evaluated by micro-computed tomography. Gene expression related to lipid and bone metabolisms was assayed with real-time quantitative polymerase chain reaction. Bone marrow cells from both genotypes were induced to differentiate into osteoblasts or osteoclasts, and treated with palmitic acid (PA). HFD increased the body weight and fat pad weight, and impaired lipid metabolism in both WT and IL6-/mice. The dysregulation of lipid metabolism was more serious in IL6-I- mice. Trabecular bone volume fraction, trabecular bone number and trabecular bone thickness were significantly downregulated in WT mice after HFD than those in the RD $(P<0.05)$. However, these bone microstructural parameters were increased by $53 \%, 34 \%$ and $40 \%$, respectively, in IL6-I- mice than those in WT mice on the HFD $(P<0.05)$. IL6-I- osteoblasts displayed higher alkaline phosphatase (ALP) activity and higher mRNA levels of Runx2 and Colla1 than those in WT osteoblasts both in the control and PA treatment group $(P<0.05)$. IL6-I- mice showed significantly lower mRNA levels of PPAR $\gamma$ and leptin and higher mRNA levels of adiponectin in comparison with WT mice on HFD. In conclusion, these findings suggested that IL6 gene deficiency antagonized HFD-induced bone loss. IL6 might bridge lipid and bone metabolisms and could be a new potential therapeutic target for lipid metabolism disturbance-related bone loss.
\end{abstract}

Correspondence should be addressed to $\mathrm{X} Y u$ Email xijieyu@hotmail.com or xijieyu@scu.edu.cn
Journal of Molecular

Endocrinology

(2016) 57, 161-170

\section{Introduction}

Obesity and osteoporosis (OP) are interrelated disorders. Generally, it is considered that body mass index (BMI) or body weight (BW) is beneficial for bone formation and low BMI or low BW is negatively correlated with bone formation (Cao 2011). However, recent studies suggested that excess fat mass is a risk factor for bone loss in humans (Pollock et al. 2007), visceral fat is an independent predictor of bone density (Russell et al. 2010) and high-fat diet feeding reduces bone mineral density (BMD) in mice (Halade et al. 2010).

Obesity affects bone metabolism through several potential mechanisms. It is well known that both adipocytes and osteoblasts are derived from the same progenitor cells: bone marrow mesenchymal stem

Published by Bioscientifica Ltd. 
cells (BMSCs). Obesity increases the differentiation of adipocytes, whereas it decreases the differentiation of osteoblasts, which leads to fat accumulation and bone mass reduction. Obesity is usually accompanied with abnormal adipokine secretion, such as leptin and adiponectin, which might exert a direct effect on bone formation or indirect effect on bone resorption. Furthermore, obesity is related to a chronic inflammation condition. Increase in circulating and tissue proinflammatory cytokines, such as tumor necrosis factor alpha (TNF- $\alpha)$, interleukin-6 (IL6) and IL1, might enhance osteoclast differentiation and bone resorption. However, the precise mechanisms underlying the relationship between obesity and skeleton metabolism are still not clear.

IL6, an important and multifunctional cytokine, is produced by a variety of cells, such as B-cells, T-cells, adipocytes and osteoblasts (Naka et al. 2002, Hassan et al. 2014). IL6 shows extensive biological activities, including immune responses, lipid metabolism and bone metabolism (Mihara et al. 2012). IL6 shows antiadipogenic effects to regulate body weight, which is similar as that of leptin. However, intracerebroventricular injection of IL6 reduces body fat in rat and increases energy expenditure in mice (Wallenius et al. 2002). On the other hand, interleukin-6-deficient (IL6-/-) mice usually show matureonset obesity, higher levels of triglyceride (TG) and verylow-density lipoprotein (VLDL) than wild-type (WT) mice (Wallenius et al. 2002). IL6 soluble receptor and IL6 receptor double transgenic mice show a decrease in body weight, total cholesterol (TC) and TG (Peters et al. 1997). Additionally, IL6 increases fat oxidation and accelerates fat decomposition, whereas inhibits lipid synthesis, which eventually reduces serum lipid levels.

IL6 also plays a key role in bone metabolism. Yang and coworkers found that IL6 ${ }^{-/}$mice showed delayed callus mineralization and remodeling compared with those in WT mice during fracture healing (Yang et al. 2007). However, the effects of IL6 on osteoblasts and osteoclasts are not always consistent, and sometimes, even opposite (Blanchard et al. 2009, Mihara et al. 2012). In osteoclasts, IL6 was reported to stimulate osteoclast precursor cells to differentiate into mature and active osteoclasts and regarded as osteoclastogenesis promoter (Udagawa et al. 1995, Yokota et al. 2014). However, another study showed that IL6 had an inhibitory role on osteoclast formation and bone resorption by inhibiting RANKL signaling pathway (Duplomb et al. 2008). IL6-null mice had decreased osteoblast numbers (Yang et al. 2007). IL6 has been reported to stimulate osteoblast differentiation in stem cells (Erices et al. 2002). On the other hand, IL6 has been shown to impair osteoblast maturation both in vitro and in vivo (Peruzzi et al. 2012). These contradictory findings suggested that IL6 may have a double role in bone metabolism.

Furthermore, the action of IL6 on the signal communication between fat and bone metabolism is not clear. In this study, we aimed to determine the pathological roles of IL6 in the high-fat diet (HFD)-induced bone loss.

\section{Materials and methods}

\section{Animals and diets}

Male wild-type (WT) C57BL/6Jmice and IL6 knockout (IL6-/-) mice (C57BL/6J background), aged 8 weeks, were obtained from the Jackson laboratory (Bar Harbor, ME, USA). All mice were housed in Plexiglas ventilated cages with ALPHA-Dri bedding within a pathogen-free facility and at a constant temperature $\left(22^{\circ} \mathrm{C}\right)$ under a $12 / 12$-h light/darkness cycle with free access to water. IL6 ${ }^{-/-}$and WT mice were randomly separated into regular diet group or high-fat diet group. Mice were fed with a high-fat diet (HFD, 60\% lipid, 20\% carbohydrate, 20\% protein, $5.2 \mathrm{Kcal} / \mathrm{g}$ ) (Table 1) or a regular diet (RD, 13\% lipid, 65\% carbohydrate, $22 \%$ protein, $3.4 \mathrm{Kcal} / \mathrm{g}$ ) for 12 weeks. Both diets were purchased from TROPHIC Animal Feed Hightech Co., Ltd (Nantong, Jiangsu, China). Body weight was recorded weekly. After 12 weeks of feeding, tissue and blood were collected for the experiments described below. All animal experiments were performed in accordance with the Guide for the Care and Use of Laboratory Animals and were approved by the Institutional Animal

Table 1 Composition and fatty acid profiles of HFD.

\begin{tabular}{|c|c|c|}
\hline HFD & $\mathbf{g}(\%)$ & Kcal (\%) \\
\hline Protein & & 20 \\
\hline Carbohydrate & & 20 \\
\hline Fat & & 60 \\
\hline Total Kcal/g & 5.2 & \\
\hline Ingredient & g & Kcal \\
\hline Casein & 258 & 1032 \\
\hline Corn starch & 0 & 0 \\
\hline Maltodextrin & 162 & 648 \\
\hline Sucrose & 89 & 356 \\
\hline Soybean oil & 32 & 288 \\
\hline Lard & 317 & 2853 \\
\hline Cellulose & 65 & \\
\hline Mineral mix, M1020 & 58 & \\
\hline Vitamin mix, V1010 & 13 & 52 \\
\hline L-Cystine & 4 & 16 \\
\hline Choline bitartrate & 3 & \\
\hline TBHQ & 0.069 & \\
\hline Total & 1000 & 5245 \\
\hline
\end{tabular}

Published by Bioscientifica Ltd 
Care and Use Committee at the West China Hospital, Sichuan University.

\section{Serum parameters for lipid metabolism}

Serum TG and TC levels were measured by enzyme method (Beijing North Kangtai reagent CO., Beijing, China). Low-density lipoprotein cholesterol (LDL-C) levels were detected by the selective precipitation method (Beijing North Kangtai reagent CO.).

\section{Micro-CT for bone mass and microstructure}

Distal ends of left femora were fixed with $4 \%$ paraformaldehyde for $24 \mathrm{~h}$ and then scanned on the vivaCT 40 microCT scanner (Scanco Medical, Basserdorf, Switzerland). Bone microstructure parameters including trabecular bone volume fraction (BV/TV), trabecular number (Tb.N), trabecular thickness (Tb.Th) and trabecular separation (Tb.Sp) were analyzed according to our early protocol (Zhou et al. 2014). Sanco software, version 5.0 was used for three-dimensional (3D) reconstruction in the region of interest (ROI) (Zhang et al. 2015).

\section{Bone histological analysis}

The femurs were fixed in $4 \%$ paraformaldehyde solution for $24 \mathrm{~h}$ and then decalcified in $20 \%$ ethylene diamine tetraacetic acid (EDTA) buffer. The buffer was changed every 4 days until the femurs were completely decalcified. The samples were dehydrated and paraffin blocks were prepared by the standard histological procedure. Longitudinal sections about $5 \mu \mathrm{m}$ from the middle of femur were used for tartrate-resistant acid phosphatase (TRAP) staining (Sigma-Aldrich, kit 387-A) and histological analysis. For each tissue sample, from the region $2 \mathrm{~mm}$ beneath the growth plate, cells were collected. TRAP-positive cells with three or more nuclei were counted as osteoclasts to evaluate the formation of osteoclasts.

\section{Real-time quantitative RT-PCR}

Total RNA was extracted from epididymal white adipose tissue (WAT), distal metaphyses of the right femurs and cultured osteoblasts with TRIzol reagent (Invitrogen, Carlsbad, CA, USA) according to the manufacturer's instructions. RNA quality was evaluated by A260/A280 ratio. Complementary DNAs (cDNAs) were synthesized from $1 \mu \mathrm{g}$ total RNA using $20 \mu \mathrm{L}$ reverse transcription
Table 2 RT-PCR primer sequences.

\begin{tabular}{|c|c|}
\hline Primer & Sequence $5^{\prime}-3^{\prime}$ \\
\hline Runx2 & $\begin{array}{l}\text { Forward: 5'-GTGGTAGGCAGTCCCACTTT-3' } \\
\text { Reverse: 5'-GAGCACTCACTGACTCGGTT-3' }\end{array}$ \\
\hline Col1a1 & $\begin{array}{l}\text { Forward: 5'-GCGAAGGCAACAGTCGCT-3' } \\
\text { Reverse: 5'-CTTGGTGGTTTTGTATTCGATGAC-3' }\end{array}$ \\
\hline OPG & $\begin{array}{l}\text { Forward: 5'-TACCTGGAGATCGAATTCTGCTT-3' } \\
\text { Reverse: 5'-CCATCTGGACATTTTTTGCAAA-3' }\end{array}$ \\
\hline RANKL & $\begin{array}{l}\text { Forward: 5'-CCTGAGGCCCAGCCATTT-3' } \\
\text { Reverse: 5'-CTTGGCCCAGCCTCGAT-3' }\end{array}$ \\
\hline Leptin & $\begin{array}{l}\text { Forward: 5'-GGAAAATGTGCTGGAGACCC-3' } \\
\text { Reverse: 5'-TACCGACTGCGTGTGTGAAAT-3' }\end{array}$ \\
\hline Adiponectin & $\begin{array}{l}\text { Forward: 5'-TGACGACACCAAAAGGGCTC-3' } \\
\text { Reverse: 5'-GAGTGCCATCTCTGCCATCA-3' }\end{array}$ \\
\hline PPAR $\gamma$ & $\begin{array}{l}\text { Forward: 5'-TTCGCTGATGCACTGCCTAT-3' } \\
\text { Reverse: 5'-TGATCGCACTTTGGTATTCTTGG-3' }\end{array}$ \\
\hline GAPDH & $\begin{array}{l}\text { Forward: 5'-TGCACCACCAACTGCTTAG-3' } \\
\text { Reverse: 5'-GGATGCAGGGATGATGTTC-3' }\end{array}$ \\
\hline
\end{tabular}

reaction solution with the PrimeScript RT reagent kit (Takara Bio). Real-time qPCR reaction was performed with SYBR Premix Ex Taq II kit (Takara Bio) in cycler PCR machine (LightCycler 96, Roche), and $2 \mu \mathrm{L}$ cDNA were amplified following the universal protocol: $94^{\circ} \mathrm{C}$ for $3 \mathrm{~min}$, then, $94^{\circ} \mathrm{C}$ for $20 \mathrm{~s}$ and $60^{\circ} \mathrm{C}$ for $20 \mathrm{~s}$ for 45 cycles. The primer sequences are listed in Table 2. GAPDH was used as an endogenous control. The relative mRNA expression levels were normalized to the GAPDH in the same sample. The data analysis was performed with the $2^{-} \triangle \triangle \mathrm{CT}$ method as in our previous report (Yu et al. 2005).

\section{Bone marrow cells culture and PA intervention}

Bone marrow cells were obtained from tibias and femurs and cultured in 24-well culture plates at a density of $1 \times 10^{6}$ cells/well in $\alpha$-MEM medium (Invitrogen) containing 10\% fetal bovine serum (FBS), 1\% penicillin, 1\% streptomycin and $1 \% \beta$-glutamine for 7 days. Culture medium was then changed to osteoblastic differentiation medium, which consisted of regular medium plus $50 \mu \mathrm{g} / \mathrm{mL}$ ascorbic acid and $10 \mathrm{mM} \beta$-glycerophosphate. Medium was changed every day for the entire duration of culture. After further culture for 7 days, cells were near-serum-starved for $12 \mathrm{~h}$, using $0.2 \%$ FBS supplemented medium, to minimize the effects of growth factors in serum. Cells were treated with $4 \times 10^{-4} \mathrm{M}$ palmitic acid (PA) in $0.3 \%$ bovine serum albumin (BSA) or just $0.3 \%$ BSA for $24 \mathrm{~h}$. Alkaline phosphatase (ALP) staining and qRT-PCR were performed to determine osteoblast differentiation and gene expression.

Bone marrow cells were also induced to differentiate into osteoclasts. The bone marrow cells were plated in 24 -well culture plates at a density of $1 \times 10^{6}$ cells/well

Published by Bioscientifica Ltd 
in the osteoclastic differentiation medium, which consisted of regular medium, $25 \mu \mathrm{g} / \mathrm{mL}$ receptor activator of nuclear factor kappa-B ligand (RANKL) and $25 \mu \mathrm{g} / \mathrm{mL}$ macrophage colony-stimulating factor (M-CSF). Medium was changed every 3 days. On day 8 , cells were near-serum-starved for $12 \mathrm{~h}$, using $0.2 \%$ FBS supplemented medium, to minimize the effects of growth factors in serum. Then, the cells were treated with $4 \times 10^{-4} \mathrm{M}$ PA for $8 \mathrm{~h}$. TRAP staining (Sigma) was performed to determine the osteoclast formation.

\section{Statistical analysis}

Statistical analysis was performed with SPSS statistic 17.0 software. Data were expressed as mean \pm standard error of the mean (s.E.M.). Analysis of variance (ANOVA) was applied for statistical analysis to assess the differences between genotypes, diet treatment and the interactions between genotype and diet treatment. $P<0.05$ was considered significant.

\section{Results}

\section{Body weight and serum lipid levels}

On the regular diet, the body weight of IL6-/- mice was significantly higher than that of WT mice at all time points tested (Fig. 1A). Body weight in both genotypes on HFD tended to increase in comparison with the corresponding mice on RD (Fig. 1A). Body weight of
WT mice on HFD increased by $18.9 \%$ compared with that of WT mice on RD after 12 weeks $(32.68 \pm 0.87$ vs $27.49 \pm 0.58 \mathrm{~g}, P<0.01)$. However, body weight of IL6 $^{-/-}$mice on HFD exhibited no significant difference compared with that of IL6 ${ }^{-/-}$mice on RD $(30.91 \pm 0.97$ vs $29.21 \pm 0.77 \mathrm{~g}$ ). Under high-fat feeding, IL6 ${ }^{-/-}$mice exhibited $11.9 \%$ less body weight than WT mice $(29.21 \pm 0.77$ vs $32.68 \pm 0.87 \mathrm{~g})$. Furthermore, high-fat diet feeding induced abnormal accumulation of the epididymal fat pad in both genotypes, but the gain of fat pad weight was $33.3 \%$ less in IL6 $^{-/-}$mice than that in WT mice (Fig. 1B).

On the regular diet, IL6 ${ }^{-/-}$mice showed significantly higher level of TC $(1.38 \pm 0.09$ vs $0.91 \pm 0.06 \mathrm{mmol} / \mathrm{L}$, $P<0.01)$ than WT mice. After high-fat feeding, the levels of TC and LDL-C increased in both genotypes. TC level increased by $90 \%(1.72 \pm 0.07$ vs $0.91 \pm 0.06 \mathrm{mmol} / \mathrm{L}$, $P<0.01)$ and $40 \%(2.06 \pm 0.11$ vs $1.38 \pm 0.09 \mathrm{mmol} / \mathrm{L}$, $P<0.01)$ in WT mice and IL6 $^{-/-}$mice, respectively (Fig. 1C). LDL-C level increased by $85 \%(0.39 \pm 0.05$ vs $0.21 \pm 0.04 \mathrm{mmol} / \mathrm{L}, \quad P<0.05)$ in WT mice and $69 \% \quad(0.44 \pm 0.07$ vs $0.26 \pm 0.09 \mathrm{mmol} / \mathrm{L}, \quad P=0.069)$ in IL6-/- mice (Fig. 1D). Furthermore, only the TC level in IL6 I- $^{-}$mice was 19\% significantly higher than that in WT mice $(2.06 \pm 0.11$ vs $1.72 \pm 0.07 \mathrm{mmol} / \mathrm{L}$, $P<0.05)$ on HFD group. These data revealed that HFD feeding worked successfully in the genotypes, but IL6 $6^{-/-}$mice showed weaker response compared with WT mice.
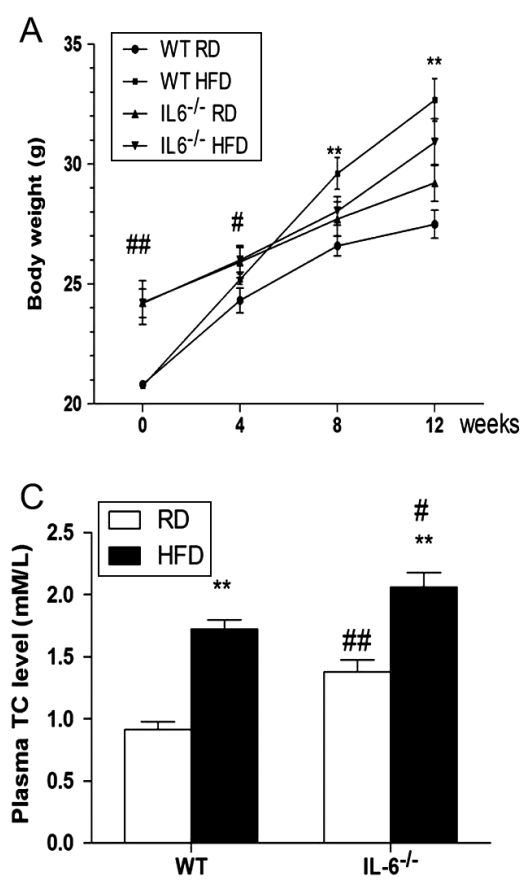
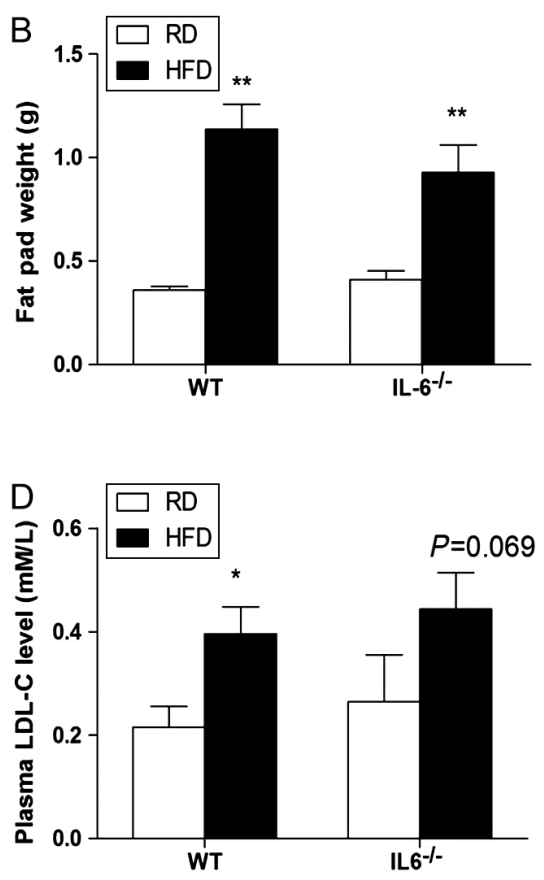

Figure 1

IL6 ${ }^{-/-}$mice showed weaker response in body weight and serum lipid levels after high-fat diet feeding. IL6-I- mice and WT mice were fed with a high-fat diet (HFD) or a regular diet (RD), body weight was recorded each week (A); after 12 weeks of feeding, the epididymal fat pad weight was measured (B); the serum levels of TC (C) and LDL-C (D) were assessed with commercial kits. $n=6$; ${ }^{*} P<0.05, * * P<0.01$, compared with the same genotype; ${ }^{\prime} P<0.05, \# P<0.01$, compared with the same diet. 
A
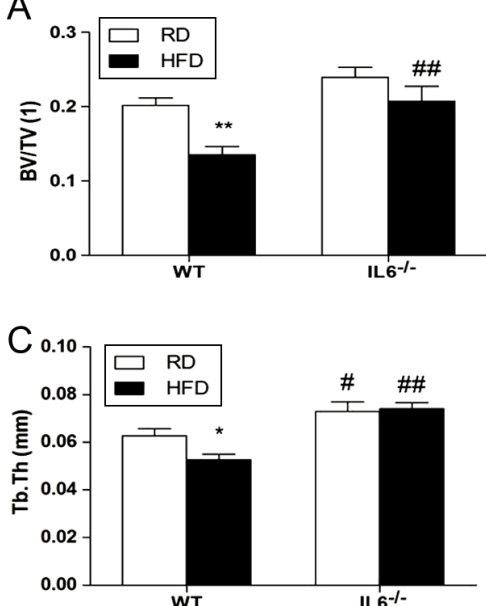

B
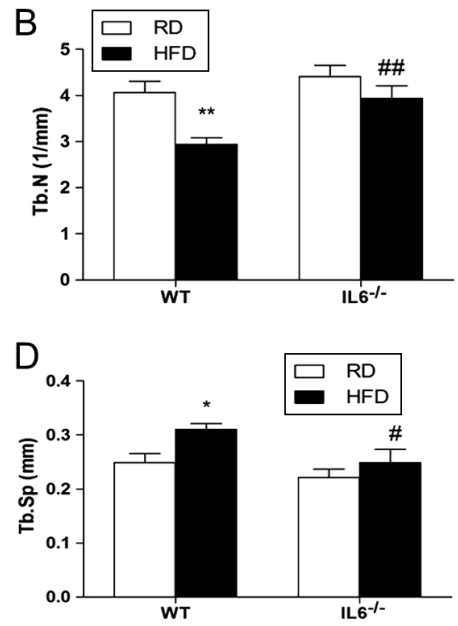

E
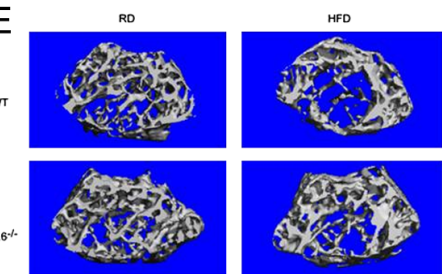

Figure 2

IL6 knockout protected HFD-induced femoral trabecular bone loss. IL6-l- mice and WT mice were fed with RD or HFD for 12 weeks. Bone microstructure parameters of the distal femur metaphysis were analyzed with micro-CT. Trabecular bone mass (A), trabecular number (B), trabecular thickness (C),

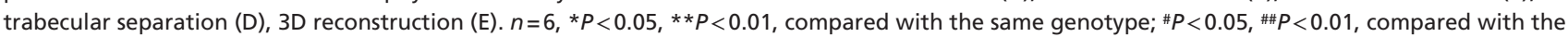
same diet. A full colour version of this figure is available at http://dx.doi.org/10.1530/JME-16-0076.

\section{Changes in bone mass and microstructure}

On regular diet, IL6-/- mice exhibited higher trabecular bone mass (volume fraction) (Tb.BV/TV) (Fig. 2A), trabecular number (Tb. N) (Fig. 2B) and trabecular thickness (Tb.Th) (Fig. 2C) and lower trabecular separation (Tb.Sp) (Fig. 2D) than those in WT mice. Only the difference in Tb.Th was significant. Under HFD feeding, Tb.BV/TV and Tb.N were decreased, and Tb.Sp was increased in both genotypes. However, only the changes in WT mice were significant. IL6 ${ }^{-/-}$mice on HFD exhibited significantly higher values of Tb.BV/TV, Tb.N and Tb.Th, but significantly lower value of Tb. Sp than WT mice on the same diet. Three-dimensional reconstruction assay also supported the fact that the HFD induced more trabecular bone loss in WT mice than that in IL6 ${ }^{-/-}$mice (Fig. 2E). These results suggested that IL6 knockout protected HFD-induced femoral trabecular bone loss.

\section{Changes in osteoblastogenesis}

On regular diet, mRNA expression of Runx2 was higher in IL6 ${ }^{-/-}$mice than that in WT mice; mRNA expression of Colla1 was similar between IL6 ${ }^{-/-}$and WT mice. After high-fat diet for 12 weeks, mRNA levels of Runx 2 and Colla1 were downregulated in WT mice, but the changes in IL6 ${ }^{-/-}$mice were not significant. Furthermore, IL6 ${ }^{-/-}$ mice demonstrated higher mRNA expression of Runx2 and Colla1 than WT mice $(P<0.01)$ (Fig. 3A and B).

To study the direct effect of fatty acid on osteoblastogenesis, PA was used to treat osteoblasts from both the genotypes. ALP staining showed that there was no notable difference in ALP activity in osteoblasts between WT mice and IL6 ${ }^{-/-}$mice under vehicle treatment. After treatment with PA, ALP activity was reduced in osteoblasts from both genotypes, but IL6-/- osteoblasts showed higher ALP activity than WT osteoblasts (Fig. 4A). The mRNA levels of Runx2 and Colla1 were significantly higher in IL6 $^{-/-}$osteoblasts
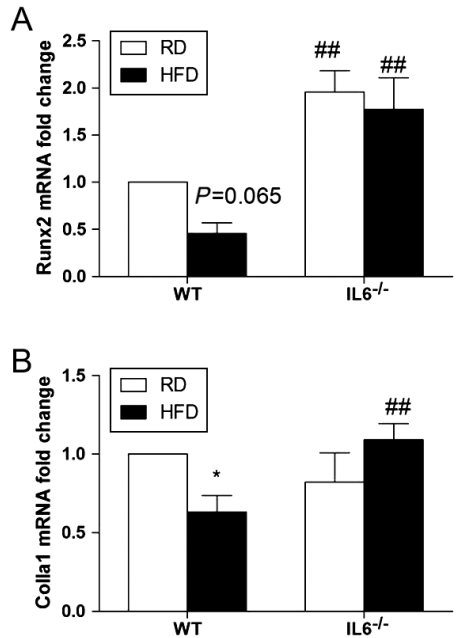

Figure 3

HFD downregulated osteoblastic gene expressions in WT mice, but not in IL6-I- mice. IL6-I- mice and WT mice were fed with RD or HFD for 12 weeks. mRNA levels of Runx2 (A) and Colla1 (B) in the distal femur metaphysis were determined with qRT-PCR. $n=5$; ${ }^{*}<0.05$, ** $P<0.01$, compared with the same genotype; ${ }^{\prime} P<0.05, \# P<<0.01$, compared with the same diet.

Published by Bioscientifica Ltd 
A
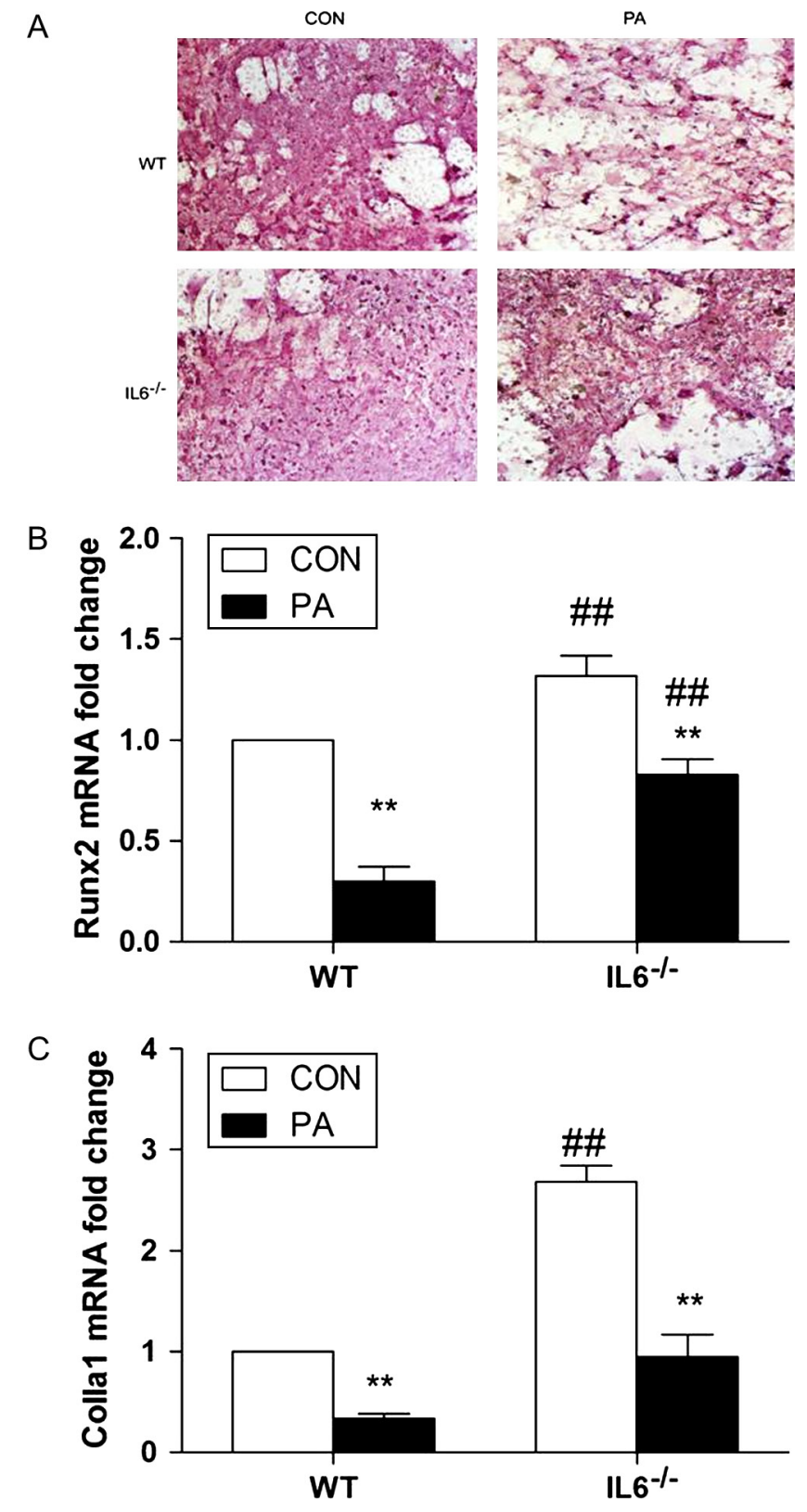

Figure 4

IL6-I- mice showed less reduction in osteoblastogenesis after PA treatment. Bone marrow stromal cells from IL6-I- mice and WT mice were induced to differentiate into osteoblasts in vitro. Osteoblasts were treated with $4 \times 10^{-4} \mathrm{M}$ palmitic acid (PA) for the last $24 \mathrm{~h}$. ALP staining, 10x magnification (A); mRNA levels of Runx2 (B) and Colla1 (C) in osteoblasts were determined with qRT-PCR. $n=6 ;{ }^{*} P<0.05, * * P<0.01$, compared with the same genotype; ${ }^{\# P}<0.05, \# P<0.01$, compared with the same treatment.

than those in WT osteoblasts under basal condition (Fig. 4B and C). After treatment with PA, mRNA levels of Runx2 and Colla1 were downregulated in both IL6-/- and WT osteoblasts in comparison with their corresponding controls. Similar to the data from in vivo study,
IL6-/- osteoblasts showed higher mRNA expressions of Runx2 and Colla1 than those in WT osteoblasts after treatment with PA.

As osteoblastogenesis is usually negatively associated with adipocyteogenesis, we studied gene expressions related to adipocyteogenesis with qRTPCR. On regular diet, mRNA level of PPAR $\gamma$ in IL6 ${ }^{-/-}$ mice was 0.79 -fold higher than that in WT mice $(P<0.05)$ (Fig. 5A), whereas mRNA levels of leptin and adiponectin were similar between IL6 $^{-/-}$mice and WT mice (Fig. 5B and C). On HFD, mRNA expressions of PPAR $\gamma$ and leptin were upregulated by 2.34 -fold and 3.24 -fold, respectively, in WT mice $(P<0.05)$, whereas no significant change was found in IL6 ${ }^{-/-}$mice. However, IL6 ${ }^{-/-}$mice showed significantly lower mRNA levels of PPAR $\gamma$ and leptin than WT mice on HFD. In contrast, HFD reduced mRNA level of adiponectin in WT mice but increased it in IL6 $6^{-/-}$mice, but both the changes were not significant. mRNA expression of adiponectin was 1.24-fold higher in IL6 ${ }^{-/-}$mice than that in WT mice on HFD $(1.21 \pm 0.25$ vs $0.54 \pm 0.09, P<0.05)$.
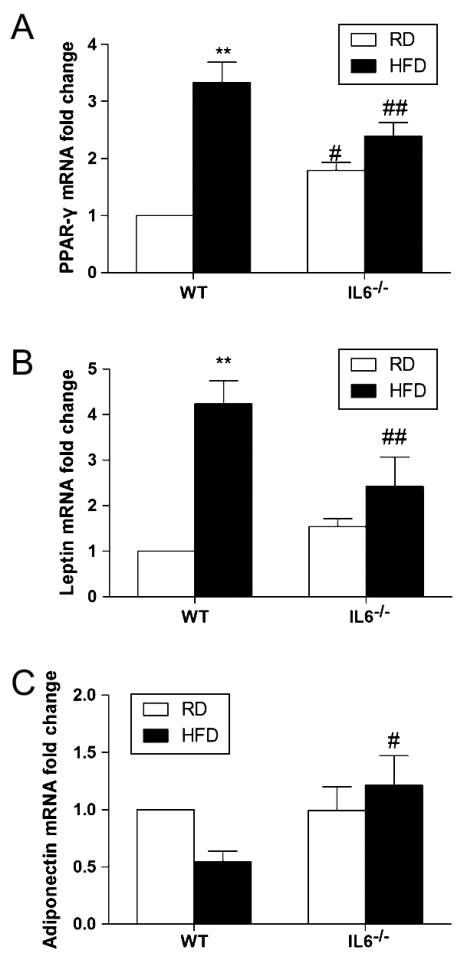

Figure 5

HFD upregulated adipocyteogenesis gene expressions in WT mice, but not in IL6- ${ }^{-/}$mice. IL6-/- and WT mice were fed with RD or HFD for 12 weeks. mRNA levels of PPARY (A), leptin (B) and adiponectin (C) in the distal femur metaphysis were determined with qRT-PCR. $n=6$; ${ }^{*} P<0.05$, $* * P<0.01$, compared with the same genotype; $\# P<0.05, \# P<0.01$, compared with the same diet.

Published by Bioscientifica Ltd 


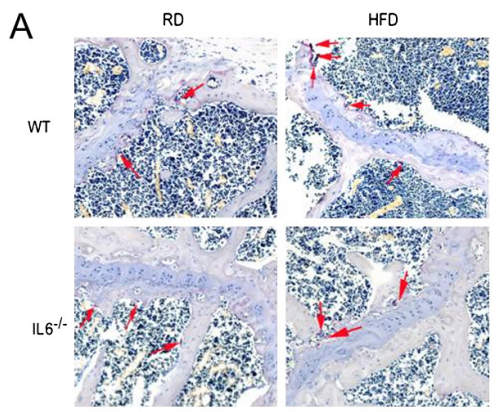

B
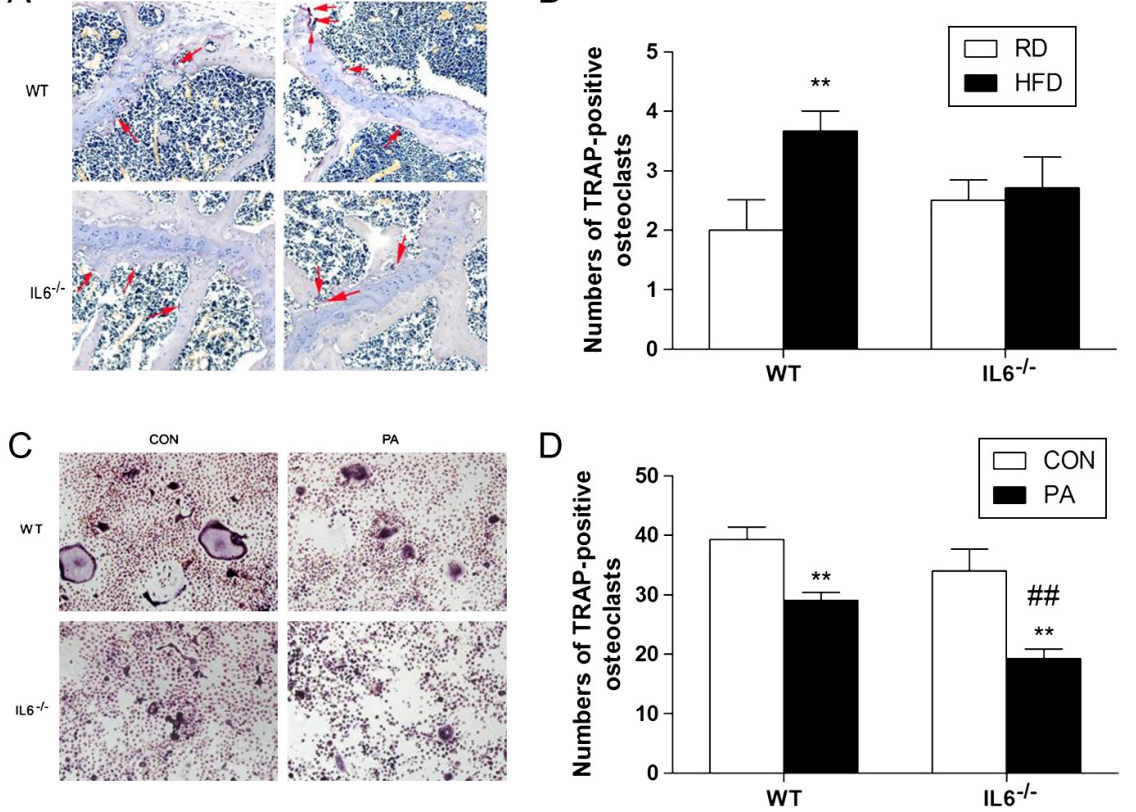

Figure 6

HFD and PA induced less reduction in osteoclastogenesis in IL6-I- mice. (A and B) IL6 ${ }^{-/-}$and WT mice were fed with RD or HFD for 12 weeks. Longitudinal sections from distal femur metaphysis were stained with TRAP to assay osteoclast formation, $20 \times$ magnification. (C and D): Bone marrow cells from IL6 ${ }^{-/-}$and WT mice were induced to differentiate into osteoclasts in vitro. Osteoclasts were treated with $4 \times 10^{-4} \mathrm{M}$ palmitic acid (PA) for the last $8 \mathrm{~h}$ and stained with TRAP to assay osteoclast formation, $10 \times$ magnification. $N=4 ; * P<0.05, * * P<0.01$, compared with the same genotype; $P<0.05$, $\# \#<<0.01$, compared with the same treatment.

\section{Changes in osteoclastogenesis}

TRAP staining showed that IL6 ${ }^{-/-}$and WT mice exhibited no significant difference in the number of TRAP-positive osteoclasts under regular diet feeding. HFD increased the number of TRAP-positive osteoclasts in both genotypes, but only the change in WT mice was significant (Fig. 6A and B). Although the number of osteoclasts was not different between IL6 ${ }^{-/}$and WT mice under RD or HFD feeding, the numbers of osteoclasts in IL6 ${ }^{-/-}$mice tended to be less than those in WT mice under HFD feeding.

To further study the direct effect of fatty acid on osteoclasts, PA was used to treat osteoclasts in vitro. TRAP staining showed that the number of TRAP-positive osteoclasts was similar between WT and IL6-/- osteoclasts on vehicle treatment (Fig. 6C and D). After treatment with PA, the number of TRAP-positive osteoclasts reduced significantly in WT and IL6 $6^{--}$osteoclasts. Furthermore, the number of TRAP-positive osteoclasts was $33.6 \%$ less in PA-treated IL6 ${ }^{-/-}$osteoclasts than in PA-treated WT osteoclasts.

\section{Discussion}

On regular diet, IL6-/- mice showed higher body weight, serum level of TC and mRNA level of Runx2 in bone. However, except higher Tb.Th in IL6-/- mice, there was no significant difference in $\mathrm{Tb} . \mathrm{BV} / \mathrm{TV}$ and $\mathrm{Tb} . \mathrm{N}$ between IL6-1-- mice and WT mice. These results indicated that IL6 gene knockout did not change skeletal phenotype significantly in mice. Kopf and Yang and coworkers also reported that IL6 knockout mice exhibited normal skeletal phenotype (Kopf et al. 1994, Yang et al. 2007). On high-fat diet, we observed that body weight, epididymal fat pad weight and serum levels of TC and LDL-C were upregulated in IL6-/- mice and WT mice. This result is consistent with previous obese model induced by high-fat diet (Lin et al. 2000, Jones et al. 2005). Our findings also showed that HFD significantly decreased Tb.BV/TV, Tb.N and Tb.Th, and increased Tb.Sp in WT mice. Our study and the studies from Halade and Cao suggested that the murine model of trabecular bone loss can be established by the high-fat diet-induced obesity (Cao et al. 2009, Halade et al. 2010). In this study, we found that the HFDinduced obesity failed to induce trabecular bone loss in IL6 ${ }^{-/-}$mice, which indicated that IL6 played a critical role in the pathological process of obesity-related trabecular bone loss.

Adipocytes and osteoblasts are derived from the same progenitor cells - BMSCs. HFD has been reported to induce BMSCs to differentiate into adipocytes rather than osteoblasts, which may be one of the reasons for HFD-related bone loss. We found that HFD feeding significantly enhanced PPAR expression and epididymal fat pad accumulation in WT mice, which was disadvantageous to bone metabolism. However, the increased level of $P P A R \gamma$ in IL6 ${ }^{-/-}$mice on HFD was much lower than that in WT mice on the same diet. Consistent with lower level of PPAR $\gamma$, the accumulation of body weight and epididymal fat pad weight was lower in IL6-I- mice on HFD than that in WT mice on the

Published by Bioscientifica Ltd. 
same diet. On the other hand, we found lower mRNA expression of Runx 2 and Colla1 in WT mice after highfat diet feeding, as well as lower ALP activity and mRNA expression of Runx 2 and Colla1 in WT osteoblasts after treatment with PA. However, we found higher mRNA level of Runx2 in IL6-/- mice after HFD and PA-treated IL6 $^{-1-}$ osteoblasts than that in WT mice and osteoblasts on the same treatment. Moreover, PA-treated IL6-/osteoblasts showed higher ALP activity than PA-treated WT osteoblasts. These results indicate that knocking out IL6 gene protects abnormal adipocyteogenesis and osteoblastogenesis induced by the HFD. IL6 has been reported to inhibit Runx2 expression and ALP activity through SHP2/MEK2, SHP2/AKT2 and insulin-like growth factor 5 (IGFBP5) signal pathway (Peruzzi et al. 2012, Kaneshiro et al. 2014). This may be the mechanism for better osteoblastogenesis in IL6 ${ }^{-/-}$mice on HFD.

It is well known that leptin and adiponectin are two important adipokines produced by adipocytes. Obesity is usually accompanied with higher level of leptin and lower level of adiponectin in the serum (Matsubara et al. 2002). Our research also confirmed that obesity induced by the high-fat diet was accompanied with the upregulation of leptin and downregulation of adiponectin in WT mice. In the obese state, IL6 is usually upregulated and acts as a positive regulator for leptin expression (Sarraf et al. 1997, Gualillo et al. 2000) and an inhibitor for adiponectin expression in adipocytes (Fasshauer et al. 2003, Ouchi $\&$ Walsh 2007). In this study, we found that HFD failed to downregulate adiponectin in IL6 ${ }^{-/-}$mice, and the change in leptin in IL6-/- mice was much lower than that in WT mice on HFD. Our data further confirmed the regulating roles of IL6 on the expressions of leptin and adiponectin. Injecting leptin intracerebroventricularly leads to bone loss, whereas leptin knockout mice show higher bone mass (Elefteriou et al. 2004). Contrary to leptin, adiponectin promotes osteoblast differentiation and inhibits osteoclast formation (Oshima et al. 2006). Our data suggested that IL6 gene knockout may reduce adipocyte differentiation and accumulation, enhance the expression of adiponectin while inhibiting the expression of leptin, thus preventing bone loss induced by the high-fat diet.

Obesity belongs to a chronic inflammatory state in which the levels of proinflammatory cytokines, such as IL1, IL6 and TNF- $\alpha$, are upregulated, which may enhance osteoclast proliferation and bone resorption (Cao 2011). Delamata and coworkers reported that IL6 enhanced the expression of parathyroid hormone-related protein $(\mathrm{PTHrP})$, which stimulated the differentiation and maturation of osteoclast precursors (Delamata et al. 1995). Our study revealed that HFD feeding significantly increased the number of the TRAP-positive osteoclasts. In contrast, knockout of IL6 attenuated abnormal osteoclast formation induced by the high-fat diet or PA treatment. These data implicated that deletion of IL6 decreased osteoclastogenesis. Moreover, normal bone remodeling depends on the dynamic balance between bone formation and bone resorption. HFD decreased bone formation but enhanced bone resorption, thus resulting in trabecular bone loss. Knockout of IL6 can weaken the negative impact of HFD on bone metabolism. Therefore, it resists the trabecular bone loss induced by the high-fat diet.

Both IL6 and TNF $\alpha$ are important proinflammatory cytokines. Our early study showed that $\mathrm{TNF}^{-/-}$mice are protected from trabecular bone loss induced by high-fat feeding (Zhang et al. 2015). In this study, we further confirmed that knockout IL6 can antagonize HFD-induced trabecular bone loss. Combining the results from our previous study (Zhang et al. 2015) and this study, we found that the changes in bone phenotypes were distinctive among $\mathrm{TNF}^{-/-}$mice, IL6 ${ }^{-/-}$mice and WT mice. On regular diet, IL6-/- mice exhibited significantly higher $\mathrm{Tb}$.Th, but $\mathrm{TNF}^{-/-}$ mice exhibited significantly higher Tb.N than WT mice. After HFD feeding, Tb.BV/TV, Tb.N and Tb.Th were downregulated, whereas Tb.Sp was upregulated in WT mice. These changes were similar in IL6 -/- $^{-/}$ mice, whereas they were reversed in $\mathrm{TNF}^{-/-}$mice. Consistent with those changes, IL6 ${ }^{-/-}$mice and $\mathrm{TNF}^{-/-}$ mice exhibited higher Runx2 and Colla1 mRNA levels than those in WT mice both on the regular diet and high-fat diet, with the highest levels in $\mathrm{TNF}^{-/-}$mice. These results indicated that both IL6 and TNF $\alpha$ play a significant role in HFD-induced trabecular bone loss, but they regulate fat and bone metabolism differently.

In conclusion, we have identified that HFD induced trabecular bone loss by reducing osteoblastogenesis and enhancing osteoclastogenesis and adipocyteogenesis. However, IL6 gene knockout resists osteogenic, adipogenic and osteoclast gene abnormalities, thus preventing HFD-induced femoral trabecular bone loss. IL6 and TNF $\alpha$ were two important factors linking fat and bone metabolism, and both played a critical role in the HFD-related trabecular bone loss, but their roles were different.

Declaration of interest

The authors declare that there is no conflict of interest that could be perceived as prejudicing the impartiality of the research reported.

Published by Bioscientifica Ltd. 


\section{Funding}

This work was funded by the National Natural Science Foundation of China, the Ministry of Education of the Peoples Republic of China, and the Chengdu Bureau of Science and Technology.

\section{Acknowledgements}

This study was supported by grants from the National Natural Science Foundation of China (No. 81370969 and 81572639 to X Yu, 31300648 to L Tian), the Ministry of Education of the People's Republic of China (No. 20130181110066 to X Yu) and the Chengdu Bureau of Science and Technology (No. 2014-HM01-00382-SF to X Yu).

\section{References}

Blanchard F, Duplomb L, Baud'huin M \& Brounais B 2009 The dual role of IL-6-type cytokines on bone remodeling and bone tumors. Cytokine \& Growth Factor Reviews 20 19-28. (doi:10.1016/j.cytogfr.2008.11.004)

Cao JJ 2011 Effects of obesity on bone metabolism. Journal of Orthopaedic Surgery and Research 6 30. (doi:10.1186/1749-799X-6-30)

Cao JJ, Gregoire BR \& Gao H 2009 High-fat diet decreases cancellous bone mass but has no effect on cortical bone mass in the tibia in mice. Bone 44 1097-1104. (doi:10.1016/j.bone.2009.02.017)

Delamata J, Uy HL, Guise TA, Story B, Boyce BF, Mundy GR \& Roodman GD 1995 Interleukin-6 enhances hypercalcemia and bone-resorption mediated by parathyroid hormone-related protein in-vivo. Journal of Clinical Investigation 95 2846-2852. (doi:10.1172/ JCI117990)

Duplomb L, Baud'huin M, Charrier C, Berreur M, Trichet V, Blanchard F \& Heymann D 2008 Interleukin-6 inhibits receptor activator of nuclear factor kappaB ligand-induced osteoclastogenesis by diverting cells into the macrophage lineage: key role of Serine727 phosphorylation of signal transducer and activator of transcription 3. Endocrinology 149 3688-3697. (doi:10.1210/en.2007-1719)

Elefteriou F, Takeda S, Ebihara K, Magre J, Patano N, Kim CA, Ogawa Y, Liu X, Ware SM, Craigen WJ, et al. 2004 Serum leptin level is a regulator of bone mass. PNAS 101 3258-3263. (doi:10.1073/ pnas.0308744101)

Erices A, Conget P, Rojas C \& Minguell JJ 2002 Gp130 activation by soluble interleukin-6 receptor/interleukin-6 enhances osteoblastic differentiation of human bone marrow-derived mesenchymal stem cells. Experimental Cell Research 280 24-32. (doi:10.1006/ excr.2002.5627)

Fasshauer M, Kralisch S, Klier M, Lossner U, Bluher M, Klein J \& Paschke R 2003 Adiponectin gene expression and secretion is inhibited by interleukin-6 in 3T3-L1 adipocytes. Biochemical and Biophysical Research Communications 301 1045-1050. (doi:10.1016/ S0006-291X(03)00090-1)

Gualillo O, Eiras S, Lago F, Dieguez C \& Casanueva FF 2000 Elevated serum leptin concentrations induced by experimental acute inflammation. Life Sciences 67 2433-2441. (doi:10.1016/S00243205(00)00827-4)

Halade GV, Rahman MM, Williams PJ \& Fernandes G 2010 High fat diet-induced animal model of age-associated obesity and osteoporosis. Journal of Nutritional Biochemistry 21 1162-1169. (doi:10.1016/j.jnutbio.2009.10.002)

Hassan W, Ding L, Gao RY, Liu J \& Shang J 2014 Interleukin-6 signal transduction and its role in hepatic lipid metabolic disorders. Cytokine 66 133-142. (doi:10.1016/j.cyto.2013.12.017)

Jones JR, Barrick C, Kim KA, Lindner J, Blondeau B, Fujimoto Y, Shiota M, Kesterson RA, Kahn BB \& Magnuson MA 2005 Deletion of PPARgamma in adipose tissues of mice protects against high fat diet-induced obesity and insulin resistance. PNAS 102 6207-6212. (doi:10.1073/pnas.0306743102)
Kaneshiro S, Ebina K, Shi K, Higuchi C, Hirao M, Okamoto M, Koizumi K, Morimoto T, Yoshikawa H \& Hashimoto J 2014 IL-6 negatively regulates osteoblast differentiation through the SHP2/MEK2 and SHP2/Akt2 pathways in vitro. Journal of Bone and Mineral Metabolism 32 378-392. (doi:10.1007/s00774013-0514-1)

Kopf M, Baumann H, Freer G, Freudenberg M, Lamers M, Kishimoto T, Zinkernagel R, Bluethmann H \& Kohler G 1994 Impaired immune and acute-phase responses in interleukin-6-deficient mice. Nature 368 339-342. (doi:10.1038/368339a0)

Lin S, Thomas TC, Storlien LH \& Huang XF 2000 Development of high fat diet-induced obesity and leptin resistance in $\mathrm{C} 57 \mathrm{Bl} / 6 \mathrm{~J}$ mice. International Journal of Obesity and Related Metabolic Disorders $\mathbf{2 4}$ 639-646. (doi:10.1038/sj.ijo.0801209)

Matsubara M, Maruoka S \& Katayose S 2002 Inverse relationship between plasma adiponectin and leptin concentrations in normal-weight and obese women. European Journal of Endocrinology 147 173-180. (doi:10.1530/eje.0.1470173)

Mihara M, Hashizume M, Yoshida H, Suzuki M \& Shiina M 2012 IL-6/IL-6 receptor system and its role in physiological and pathological conditions. Clinical Science 122 143-159. (doi:10.1042/ CS20110340)

Naka T, Nishimoto N \& Kishimoto T 2002 The paradigm of IL-6: from basic science to medicine. Arthritis Research 4 S233-S242. (doi:10.1186/ar565)

Oshima K, Nampei A, Matsuda M, Iwaki M, Fukuhara A, Hashimoto J, Yoshikawa H \& Shimomura I 2006 Adiponectin increases bone mass by suppressing osteoclast and activating osteoblast. Bone 38 S29-S29. (doi:10.1016/j.bone.2006.01.119)

Ouchi N \& Walsh K 2007 Adiponectin as an anti-inflammatory factor. Clinica Chimica Acta 380 24-30. (doi:10.1016/j.cca.2007. 01.026)

Peruzzi B, Cappariello A, Del Fattore A, Rucci N, De Benedetti F \& Teti A 2012 c-Src and IL-6 inhibit osteoblast differentiation and integrate IGFBP5 signalling. Nature Communications 3 630. (doi:10.1038/ ncomms1651)

Peters M, Schirmacher P, Goldschmitt J, Odenthal M, Peschel C, Fattori E, Ciliberto G, Dienes HP, Meyer zum Buschenfelde KH \& Rose-John S 1997 Extramedullary expansion of hematopoietic progenitor cells in interleukin IL-6-sIL-6R double transgenic mice. Journal of Experimental Medicine 185 755-766. (doi:10.1084/jem. 185.4.755)

Pollock NK, Laing EM, Baile CA, Hamrick MW, Hall DB \& Lewis RD 2007 Is adiposity advantageous for bone strength? A peripheral quantitative computed tomography study in late adolescent females. American Journal of Clinical Nutrition $\mathbf{8 6}$ $1530-1538$.

Russell M, Mendes N, Miller KK, Rosen CJ, Lee H, Klibanski A \& Misra M 2010 Visceral fat is a negative predictor of bone density measures in obese adolescent girls. Journal of Clinical Endocrinology and Metabolism 95 1247-1255. (doi:10.1210/ jc.2009-1475)

Sarraf P, Frederich RC, Turner EM, Ma G, Jaskowiak NT, Rivet DJ, Flier JS, Lowell BB, Fraker DL \& Alexander HR 1997 Multiple cytokines and acute inflammation raise mouse leptin levels: Potential role in inflammatory anorexia. Journal of Experimental Medicine 185 171-175. (doi:10.1084/jem. 185.1.171)

Udagawa N, Takahashi N, Katagiri T, Tamura T, Wada S, Findlay DM, Martin TJ, Hirota H, Taga T, Kishimoto T, et al. 1995 Interleukin IL-6 induction of osteoclast differentiation depends on IL-6 receptors expressed on osteoblastic cells but not on osteoclast progenitors. Journal of Experimental Medicine 182 1461-1468. (doi:10.1084/ jem.182.5.1461)

Wallenius V, Wallenius K, Ahren B, Rudling M, Carlsten H, Dickson SL, Ohlsson C \& Jansson JO 2002 Interleukin-6-deficient mice develop

Published by Bioscientifica Ltd. 
mature-onset obesity. Nature Medicine 8 75-79. (doi:10.1038/ nm0102-75)

Yang X, Ricciardi BF, Hernandez-Soria A, Shi Y, Pleshko Camacho N \& Bostrom MP 2007 Callus mineralization and maturation are delayed during fracture healing in interleukin-6 knockout mice. Bone $\mathbf{4 1}$ 928-936. (doi:10.1016/j.bone.2007.07.022)

Yokota K, Sato K, Miyazaki T, Kitaura H, Kayama H, Miyoshi F, Araki Y, Akiyama Y, Takeda K \& Mimura T 2014 Combination of tumor necrosis factor alpha and interleukin-6 induces mouse osteoclast-like cells with bone resorption activity both in vitro and in vivo. Arthritis \& Rheumatology 66 121-129. (doi:10.1002/ art.38218)
Yu X Ibrahimi OA, Goetz R, Zhang F, Davis SI, Garringer HJ, Linhardt RJ, Ornitz DM, Mohammadi M \& White KE 2005 Analysis of the biochemical mechanisms for the endocrine actions of fibroblast growth factor-23. Endocrinology 146 4647-4656. (doi:10.1210/en.2005-0670)

Zhang K, Wang C, Chen Y, Ji X, Chen X, Tian L \& Yu X 2015 Preservation of high-fat diet-induced femoral trabecular bone loss through genetic target of TNF-alpha. Endocrine 50 239-249. (doi:10.1007/s12020-015-0554-5)

Zhou M, Ma J, Chen S, Chen X \& Yu X 2014 MicroRNA-17-92 cluster regulates osteoblast proliferation and differentiation. Endocrine $\mathbf{4 5}$ 302-310. (doi:10.1007/s12020-013-9986-y)

Received in final form 1 August 2016

Accepted 4 August 2016

Accepted Preprint published online 4 August 2016
Published by Bioscientifica Ltd. 